\title{
Prevalence of overweight and metabolic syndrome, and associated sociodemographic factors among adult Ecuadorian populations: the ENSANUT-ECU study
}

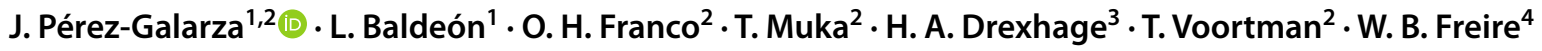

Received: 12 September 2019 / Accepted: 18 April 2020 / Published online: 19 May 2020

(c) The Author(s) 2020

\begin{abstract}
Background Obesity and metabolic syndrome (MetS) are key risk factors for type 2 diabetes and cardiovascular disease. Little information exists on the prevalence of obesity and MetS in Latin America and specifically in Ecuador. We aimed to estimate the prevalence of overweight, obesity, and MetS among adults in Ecuador.

Methods We analyzed data from a nation-wide population-based survey in Ecuador (ENSANUT-ECU) among 10,318 participants (3684 men, 6634 women; age range: 18-59 years) conducted in 2012. Data related to residential location (urban versus rural), altitude ( $<500,500-1500$ or $>1500 \mathrm{~m}$ above sea level (MASL)), region (highland, coast, amazon, or Galápagos), and socioeconomic status were collected. BMI, waist circumference, blood lipids, glucose, and blood pressure were measured by trained fieldworkers following standardized procedures.

Results The age-standardized prevalence of overweight was 39.5\%; $22.3 \%$ was obese; and $31.2 \%$ had MetS. The prevalence of obesity, low HDL-cholesterol, and abdominal obesity were higher in women than in men, whereas men had a higher prevalence of hypertension $(p<0.05)$. Sex differences were not observed regarding the prevalence of combined MetS. Prevalence of both obesity and MetS was higher in urban areas, at low altitude regions (coast and Galapagos), and at high socioeconomic status (all $p<0.05$ ).

Conclusions Prevalence of obesity and MetS in Ecuador are high. There are important demographic differences in the prevalence of MetS between Ecuadorian subpopulations that requires targeted research and prevention efforts, to hold and reduce the current public health problem of metabolic disorders.
\end{abstract}

Keywords Overweight · Obesity $\cdot$ Metabolic syndrome $\cdot$ Demographics

\section{Introduction}

Electronic supplementary material The online version of this article (https://doi.org/10.1007/s40618-020-01267-9) contains supplementary material, which is available to authorized users.

J. Pérez-Galarza

jmperez@uce.edu.ec

1 Instituto de Investigación en Biomedicina (INBIOMED), Universidad Central del Ecuador, Quito, Ecuador

2 Department of Epidemiology, Erasmus University Medical Center Rotterdam, Rotterdam, The Netherlands

3 Department of Immunology, Erasmus University Medical Center Rotterdam, Rotterdam, The Netherlands

4 Instituto de Investigación y Nutrición, Universidad San Francisco de Quito, Quito, Ecuador
There has been a dramatic epidemiologic transition from infectious diseases to non-communicable diseases in the past decades in developing countries [1]. This transition could be explained by the increased overweight prevalence $[2,3]$ which is associated with higher risk of developing metabolic syndrome (MetS), cardiovascular diseases (CVD), and diabetes mellitus type 2 (DM2), which are currently the leading causes of morbidity and death in Latin America and worldwide [4-6].

In Latin America, Mexico has the highest prevalence of cardiometabolic risk factors, with an estimated $67 \%$ of the population being overweight or obese [3], and 50\% in the population older than 20 years having MetS [7]. Meanwhile, the prevalence of overweight and obesity is also high in other LatinAmerican countries, with estimates varying from 20 to $50 \%$ 
$[3,8]$, while the prevalence of MetS was recently estimated to be around $25 \%$ in the population between 18 and 65 years old, where low HDL-cholesterol and abdominal obesity were the most frequent components [7]. This high prevalence of MetS could be explained by the epidemiological transition, globalization, migration (from rural to urban areas), and corresponding changes in patterns of physical activity to a more sedentary life style, and shifts from diets based on natural or minimally processed foods and high in Andean grains and vegetables to a diet high in processed and ultra-processed foods and sugarsweetened beverages [2, 9]. For Ecuador, there is not much information in a national context; data available so far are based only on the population of the capital city, Quito for which it was reported that $20 \%$ of women and $7.5 \%$ of men between 25 and 64 years of age have MetS [10]. In another study in a population older than 65 years in Quito, the prevalence of MetS was estimated to be $40 \%$ [11]. However, like other Andean nations in Latin America, Ecuador has a huge diversity with four different geographical regions (highlands, amazon, coast, and Galapagos Islands), each one with its own foods habits, altitude [from 0 to over $3000 \mathrm{~m}$ above sea level (MASL)], genetic background, economic status, and levels of urbanization [12]. Furthermore, there are several different ethnic groups in Ecuador with most being mestizos (Indian with European mix), 32 distinct Amerindian tribes, African descendants, Mulatos (African descendants with European mix), and Caucasian populations in low proportion [12]. A recent survey in China has shown a wide variability in MetS prevalence between rural and urban areas, and between regions [13], but whether this is also the case for Ecuador this is unknown. Consequently, it is important to establish the metabolic condition of Ecuadorian population taken in consideration socioeconomic status, geographical location, altitude, and ethnic origin that will allow a better estimation of the population burden of MetS and the implementation of new and more effective prevention strategies.

To achieve this goal, the Health Ministry of Ecuador conducted a large national health and nutrition survey (hereafter, ENSANUT-ECU), in which details on the socioeconomic status, nutrition, and health of the Ecuadorian population between the age of $0-59$ years were evaluated.

Using data obtained in the ENSANUT-ECU survey, we aim to address the distribution and prevalence of overweight and MetS, and to study differences by gender, socioeconomic status (SES), ethnicity, and geographical location among the inhabitants of Ecuador.

\section{Methods}

\section{Study population}

The nation-wide cross-sectional population-based survey, ENSANUT-ECU, was based on a multi-stage, stratified sample design in nationally representative population aged 0-59 years in Ecuador [14, 15]. The population was stratified by rural and urban areas, regions, and provinces. For each province, 64 census tracts were initially preselected from which 12 occupied households were selected by simple random sampling. For 57,727 individuals from 19,803 households, information on sociodemographic characteristics and anthropometric measurements were collected. From a random subsample of 14,989 persons, a venous blood and urine specimens were collected.

The ENSANUT-ECU study was approved by the Institutional Review Board of the San Francisco de Quito University. All participants signed informed consent forms, and all data were pseudonymized during data entry and analysis [14].

For the current study, participants aged 18-59 years with complete information on sociodemographic and biochemistry data were selected. This resulted in a study population of 10,318 participants (3684 men and 6634 women). Data from 12 questionnaires were collected, from which for the current study, the following data were used: socioeconomic and demographic information; data related to location (urban or rural), and altitude $[<500,500-1,500$ or $>1,500 \mathrm{~m}$ above the see level (MASL)], region (highland, coast, amazon, or Galápagos). In addition, we used data that were collected from measurements: anthropometry, blood pressure; and the following biomarkers: total cholesterol, HDL-cholesterol, triglycerides, and fasting plasma glucose.

\section{Data collection}

Applied structured questionnaires and measurements to participants in the selected households was performed by trained fieldworkers with the use of standardized procedures, protocols, and equipment [16]. Height was measured in subjects using portable stadiometers to the nearest $0.1 \mathrm{~cm}$. Abdominal circumference was measured with standard tape measure to the nearest $0.1 \mathrm{~cm}$. Portable electronic scales were used to measure weight in adults to the nearest $0.1 \mathrm{~kg}$. Anthropometric data were collected twice for each variable with an interval of 5-10 min, to ensure reliability, and the mean of the two measurements was used. Blood pressure was measured twice using a digital sphygmomanometer. If there was a difference of $\pm 0.5 \mathrm{~kg}$ in weight, $\pm 0.5 \mathrm{~cm}$ in height or abdominal circumference, or $\pm 10 \mathrm{mmHg}$ in blood pressure, a third measure was taken, and the two closest values were used to calculate the mean. To ensure the quality of the data, supervisors re-measured weight and height of participants in every tenth household, and interviewers were retrained every 11 days of fieldwork. National identity cards were used 
to verify participants' age. Using the standardized procedures, venous blood and urine samples for biochemical determinations were collected [14]. Blood concentrations of total cholesterol, HDL-cholesterol, triglycerides, and glucose were measured using an automated enzymaticcolorimetric assay Modular Pre-Analytics Evo analyzer (Roche Diagnostics).

\section{Definitions of overweight, metabolic syndrome, and triads}

BMI was calculated as weight in kilograms divided by the square of height in meters $\left(\mathrm{kg} / \mathrm{m}^{2}\right)$. Underweight was defined as a BMI $<18.5 \mathrm{~kg} / \mathrm{m}^{2}$, overweight as BMI $\geq 25$ and $<30 \mathrm{~kg} /$ $\mathrm{m}^{2}$, and obesity as BMI $\geq 30 \mathrm{~kg} / \mathrm{m}^{2}$ [17]. MetS was defined according to the harmonized criteria of a joint interim statement of the International Diabetes Federation task force [18] as the presence of three or more of the following risk factors: elevated waist circumference (men $\geq 90$, women $\geq 80 \mathrm{~cm}$ ), elevated triglycerides $(\geq 150 \mathrm{mg} / \mathrm{dL})$, reduced HDL-C $(\leq 40 \mathrm{mg} / \mathrm{dL}$ ), elevated blood pressure (systolic $\geq 130$ and/or diastolic $\geq 85 \mathrm{~mm} \mathrm{Hg}$ ), or elevated fasting glucose $(\geq 100 \mathrm{mg} / \mathrm{dL}$ ). In addition to MetS, we defined combinatory dangerous triads, which have been shown to be associated with higher CVD and overall mortality, as the combination of abdominal obesity, high blood pressure, and hyperglycemia and the combination of low HDL, high blood pressure, and hypertriglyceridemia [6].

\section{Sociodemographic factors}

For obtaining an approximate index of economic welfare, a factor analysis was used based on 42 variables. The variables used in this procedure were those related to home ownership, household equipment, and characteristics of housing variables, such as ownership of kitchen equipment, laptop, desktop, conventional television, led television, or a DVD player, on which information was obtained from the questionnaires. Once estimated, the model builds a score by means of a regression. With this technique, an index of economic welfare was obtained, which summarizes the structure of variance and covariance of all the 42 variables included. The score was estimated at the level of the household. A higher score represents a better economical position for that household. We categorized the score into quintiles that were then used as a categorical variable. Those households in the lowest quintile (Q1) are those households with the poorest economic conditions in terms of characteristics of housing and holding assets, while those in the highest quintile (Q5) represent households with better economic conditions [14].
The altitude of the households was determined by GPS devices and was categorized into meters above sea level (MASL). Ecuador has four regions: the coast region is located between the Pacific Ocean by the east and the Andes mountains by the west; the highlands correspond to the Andean mountains that cross Ecuador from South to North and divided the territorial land in three regions; the Amazon region is founded between the east border of the Andes mountains and the borders of Colombia and Peru in the west; and the Galapagos Islands that is the archipelago de Galapagos (see Fig. 1, which summarizes the metabolic abnormalities of each region). The coast and the Galapagos represent 3222 of 3279 inhabitants at 0-500 MASL region, 1333 individuals of the Amazon also belong to the 2114 subjects from 501-1500 MASL, and the 4037 participants from the highlands are also part of the group of 4925 living $>1501$ MASL. The capitals of the provinces and the head of the cantons (Provinces are divided in cantons) are considered urban areas.

\section{Statistical analysis}

Both crude and age-standardized prevalence of overweight, obesity, and Mets were calculated using the overall 2010 population census distribution for Ecuador [19]. We stratified age standardization by gender to be able to compare men and women. Data are presented as percentages, means with SDs, or medians with range, depending the type of analysis. We provide the estimates of the prevalence of overweight, obesity, and Mets in our whole-study population and stratified by gender, age, area of residence, region, altitude, ethnicity, and socioeconomic status. For the age-stratified analysis, we split the population into four age groups: 18-29, $30-39,40-49$, and 50-59 years old. We compared differences between groups using Chi-square tests, $t$ tests, and ANOVA depending the nature of the variable analyzed, and we examined correlations with Spearman's test. Figures were performed using GraphPad Prism version 5.00 for Windows, GraphPad Software, San Diego, California, USA.

\section{Results}

\section{General description of the study population}

Table 1 describes the general characteristics of the study population stratified by the presence or absence of MetS and by sex. As expected, age, weight, waist circumference, BMI, lipids, and fasting plasma glucose were on average higher in the population with MetS. 


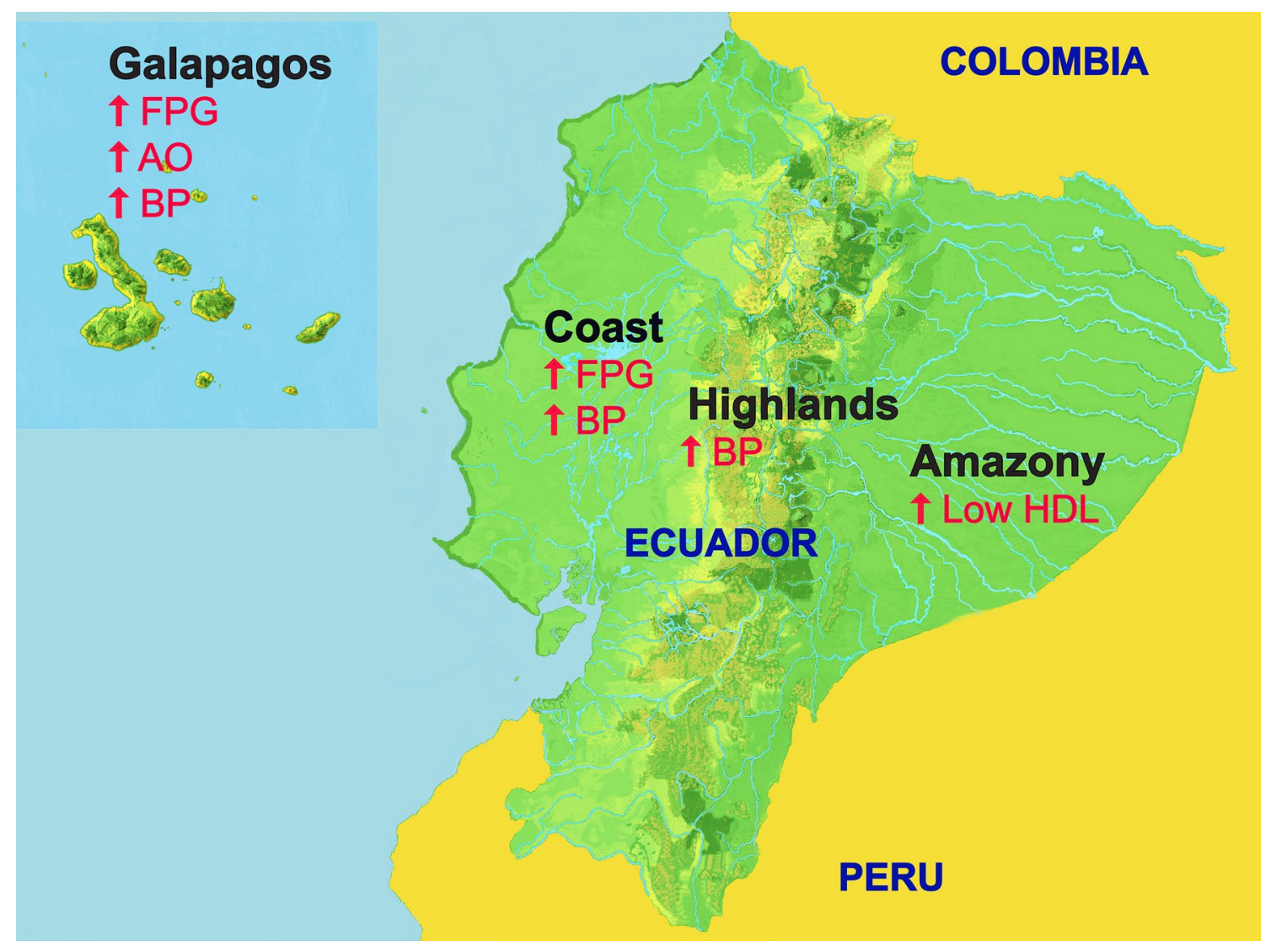

Fig. 1 Figure of the map of Ecuador that summarizes the significant metabolic abnormalities on each region. All the metabolic abnormalities highlighted on each region are significant against at least another region $(p<0.05)$

\section{Overweight, obesity and MetS by age, sex, and ethnic origin.}

Overweight or obesity was present in $57 \%$ of men and in $65.7 \%$ of women (Fig. 2). This higher prevalence among women as compared to men was mainly driven by a higher prevalence of obesity (BMI $>30)(25.9 \%$ versus $15.4 \%$ in men, $p<0.001$ ) (Fig. 2). Despite the higher prevalence of overweight and obesity in women, there was no significant difference in MetS between genders, with 31.5\% of men and $30.8 \%$ of women having MetS (Fig. 2). MetS prevalence was higher in older adults and was three times higher in the age groups $40-49$ and 50-59 (45.4\% and $49.1 \%$, respectively), in comparison with the age group of 18-29 years (16.1\%) (Table 1). The prevalence of MetS was twice higher in mestizos and other ethnic groups than the indigenous population (Table 1).

\section{MetS by sex}

Table 2 shows that men had a lower prevalence of abdominal obesity, low HDL-cholesterol, and overweight and obesity, whereas women had lower prevalence of hypertriglyceridemia and hypertension. The age-standardized prevalence of the cumulative numbers of the metabolic abnormalities of the MetS shows that only one-third of the female population have no abnormalities compared to one quarter of the male population. In line with this, men more often had more abnormalities than women (Table 3) (see Table, Online Resource 1, which illustrates the age-standardized prevalence of the accumulative risk factors of the metabolic syndrome by subregion, area, altitude, region, and socioeconomic quintiles and by gender).

\section{Overweight, obesity and MetS in urban versus rural areas}

The population living in urban areas had higher MetS $(33.7 \%)$ than those in rural areas $(27.0 \%)(p<0.001)$. This 
Table 1 Characteristics of participants by gender and by metabolic syndrome status

\begin{tabular}{|c|c|c|c|c|}
\hline & \multicolumn{4}{|l|}{ Metabolic syndrome } \\
\hline & $\begin{array}{l}\text { Men without MetS } \\
68.5 \%(2523)\end{array}$ & $\begin{array}{l}\text { Men with MetS } \\
31.5 \% \text { (1161) }\end{array}$ & $\begin{array}{l}\text { Women without MetS } \\
69.2 \%(4588)\end{array}$ & $\begin{array}{l}\text { Women with MetS } \\
30.8 \% \text { (2046) }\end{array}$ \\
\hline Age $(\text { years })^{\mathrm{c}}(10,318)$ & $30(41)$ & $38(41)$ & $32(41)$ & $39(41)$ \\
\hline \multicolumn{5}{|l|}{  } \\
\hline $18-29(3711)$ & $82.6 \%(1217)$ & $17.4 \%(257)$ & $84.8 \%(1897)$ & $15.2 \%(340)$ \\
\hline $30-39(3334)$ & $64.4 \%(709)$ & $35.6 \%(392)$ & $68.4 \%(1527)$ & $31.6 \%(706)$ \\
\hline $40-49(2540)$ & $53.9 \%(435)$ & $46.1 \%(372)$ & $55.0 \%(953)$ & $45.0 \%(780)$ \\
\hline $50-59(733)$ & $53.6 \%(162)$ & $46.4 \%(140)$ & $49.0 \%(211)$ & $51.0 \%(220)$ \\
\hline Weight $(\mathrm{kg})^{\mathrm{a}}(10,318)$ & $66.7(10.9)$ & $79.9(11.8)$ & $60.3(11.3)$ & $69.7(12.1)$ \\
\hline Height $(m)^{a}(10,318)$ & $1.7(0.1)$ & $1.7(0.1)$ & $1.5(0.1)$ & $1.5(0.1)$ \\
\hline Waist circumference $(\mathrm{cm})^{\mathrm{a}}(10,318)$ & $84.7(9.5)$ & $98.5(9.1)$ & $84.6(10.4)$ & $94.9(9.9)$ \\
\hline $\operatorname{SBP}(\mathrm{mmHg})^{\mathrm{a}}(10,318)$ & $118.5(10.7)$ & $128.1(14.0)$ & $111.4(11.2)$ & $122.3(15.8)$ \\
\hline $\operatorname{DBP}(\mathrm{mmHg})^{\mathrm{a}}(10,318)$ & $73.5(8.5)$ & 80.7 (9.9) & $69.2(8.1)$ & $76.0(10.3)$ \\
\hline Total cholesterol $(\mathrm{mg} / \mathrm{dL})^{\mathrm{a}}(10,318)$ & $174.0(36.5)$ & $192.0(38.0)$ & $171.3(35.9)$ & $190.0(36.6)$ \\
\hline LDL-cholesterol $(\mathrm{mg}-\mathrm{dL})^{\mathrm{a}}(10,085)$ & $105.5(31.6)$ & $115.4(33.8)$ & $104.2(29.8)$ & $115.1(32.5)$ \\
\hline HDL-cholesterol (mg/dL) ${ }^{\mathrm{a}}(10,318)$ & $45.8(11.0)$ & $34.4(7.1)$ & $48.4(12.1)$ & $38.3(7.9)$ \\
\hline Triglycerides $(\mathrm{mg} / \mathrm{dL})^{\mathrm{c}}(10,318)$ & $101(374)$ & $199(351)$ & $88(349)$ & $173(365)$ \\
\hline Glucose $(\mathrm{mg} / \mathrm{dL})^{\mathrm{a}}(10,318)$ & $86.9(11.5)$ & $100.7(37.1)$ & $86.2(11.0)$ & $102.0(38.8)$ \\
\hline $\operatorname{BMI}\left(\mathrm{kg} / \mathrm{m}^{2}\right)^{\mathrm{a}}(10,318)$ & $24.5(3.5)$ & $29.2(3.6)$ & $26.0(4.4)$ & $30.2(4.8)$ \\
\hline \multicolumn{5}{|l|}{ BMI groups $\left(\mathrm{Kg} / \mathrm{m}^{2}\right)^{\mathrm{b}}(10,318)$} \\
\hline Underweight $(<18.5)$ & $96.5 \%(55)$ & $3.5 \%(2)$ & $97.8 \%(90)$ & $2.2 \%(2)$ \\
\hline Normal (18.5-25) & $93.5 \%(1427)$ & $6.5 \%(100)$ & $90.6 \%(1983)$ & $9.4 \%(206)$ \\
\hline Overweight (25-30) & $58.2 \%(891)$ & $41.8 \%(640)$ & $65.1 \%(1712)$ & $34.9 \%(916)$ \\
\hline Class I obesity (30-35) & $26.5 \%(126)$ & $73.5 \%(350)$ & $50.3 \%(633)$ & $49.7 \%(626)$ \\
\hline Class II/III obesity (35-40) & $26.1 \%(24)$ & $73.9 \%(68)$ & $36.6 \%(169)$ & $63.4 \%(293)$ \\
\hline \multicolumn{5}{|l|}{ Ethnic origin $^{b}(10,318)$} \\
\hline Indigenous (952) & $84.5 \%(277)$ & $15.5 \%(51)$ & $76.6 \%(478)$ & $23.4 \%(146)$ \\
\hline Mestizo (8377) & $66.5 \%(1971)$ & $33.5 \%(992)$ & $68.1 \%(3685)$ & $31.9 \%(1729)$ \\
\hline Others (989) & $70.0 \%(275)$ & $30.0 \%(118)$ & $71.3 \%(425)$ & $28.7 \%(171)$ \\
\hline \multicolumn{5}{|l|}{ Altitude $^{b}(10,318)$} \\
\hline $0-500 \mathrm{~m}(4372)$ & $64.2 \%(1043)$ & $35.8 \%(581)$ & $67.0 \%(1840)$ & $33.0 \%(908)$ \\
\hline 501-1500 m (1819) & $71.3 \%(427)$ & $28.7 \%(172)$ & $73.2 \%(893)$ & $26.8 \%(327)$ \\
\hline$>1500 \mathrm{~m}(4127)$ & $72.1 \%(1053)$ & $27.9 \%(408)$ & $69.6 \%(1855)$ & $30.4 \%(811)$ \\
\hline \multicolumn{5}{|l|}{ Sub regions ${ }^{b}(10,318)$} \\
\hline Highlands (4925) & $71.1 \%(1240)$ & $28.9 \%(504)$ & $69.5 \%(2210)$ & $30.5 \%(971)$ \\
\hline Coast (2957) & $63.7 \%(722)$ & $36.3 \%(412)$ & $65.9 \%(1201)$ & $34.1 \%(622)$ \\
\hline Amazon (2114) & $72.0 \%(502)$ & $28.0 \%(195)$ & $74.0 \%(1049)$ & $26.0 \%(368)$ \\
\hline Galapagos (322) & $54.1 \%(59)$ & $45.9 \%(50)$ & $60.1 \%(128)$ & $39.9 \%(85)$ \\
\hline \multicolumn{5}{|l|}{$\operatorname{Area}^{b}(10,318)$} \\
\hline Urban (6565) & $65.1 \%(1559)$ & $34.9 \%(837)$ & $67.6 \%(2818)$ & $32.4 \%(1351)$ \\
\hline Rural (3753) & $74.8 \%(964)$ & $25.2 \%(324)$ & $71.8 \%(1770)$ & $28.0 \%(695)$ \\
\hline
\end{tabular}

$S B P$ systolic blood pressure, $D B P$ diastolic blood pressure, $F P G$ fasting plasma glucose

${ }^{\mathrm{a}}$ Data are mean (standard deviation), ${ }^{\mathrm{b}}$ Data are in percentage (number), ${ }^{\mathrm{c}}$ Data are in median (range)

difference between urban and rural areas was especially pronounced for men $(34.9 \%$ of men in urban versus $25.2 \%$ of men in rural areas) (Table 1). The prevalence of overweight and obesity and of all MetS components, except for low HDL, was higher in urban populations. These differences were again mainly based on differences in men living in urban versus rural areas, while urban versus rural women differed to a smaller extent (see Table, Online Resource 2 , which describes the age-standardized prevalence of the individual components of the metabolic syndrome and 


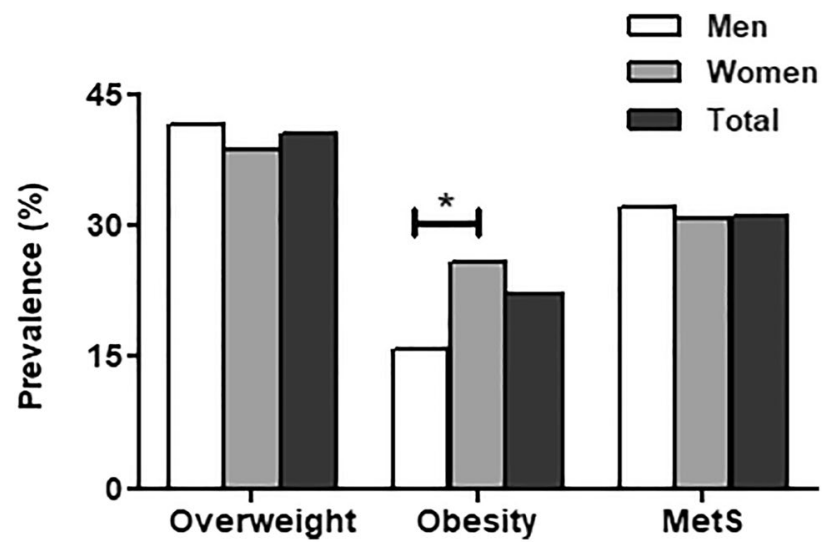

Fig. 2 Age-standardized prevalence of overweight, obesity, and metabolic syndrome (MetS) in adults aged $18-59$ in Ecuador. ${ }^{*} p<0.001$

Table 2 Crude and age-standardized prevalence of the metabolic syndrome

\begin{tabular}{ll}
\hline MetS & \\
\hline Crude & $35.9(34.6-37.1)$ \\
Gender & \\
Men & $32.1(30.3-33.9)$ \\
Women & $30.8(29.4-32.1)$ \\
Area & \\
Urban & $33.7(32.2-35.1)^{*}$ \\
Rural & $27.0(25.3-28.6)$ \\
Altitude & \\
$0-500$ & $34.1(32.3-35.8)^{*}$ \\
501-1500 & $27.4(25.0-29.8)$ \\
$>1500$ & $29.5(27.9-31.2)$ \\
Subregion & \\
Highland & $29.9(28.4-31.5)$ \\
Coast & $35.0(32.8-37.1)^{*}$ \\
Amazon & $26.6(24.4-28.8)$ \\
Galapagos & $41.9(34.9-49.0)^{*}$ \\
Economic quintile & \\
Q1 & $23.6(21.6-25.6)$ \\
Q2 & $30.4(28.1-32.7)^{*}$ \\
Q3 & $34.3(31.8-36.8)^{*}$ \\
Q4 & $35.9(33.2-38.6)^{* a}$ \\
Q5 & $32.4(29.7-35.0)^{*}$ \\
\hline
\end{tabular}

Results are age-standardized rate $(95 \% \mathrm{CI})$

*Significant differences ( $p$ value $<0.05$ ) compared to rural, 501-1500

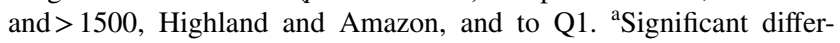
ence of Q4 compared to Q2

overweight and obesity by area, altitude, region, and socioeconomic quintiles and by gender). In line with this, urban populations had higher prevalence of 3,4 , and 5 abnormalities, again mainly explained by differences in men (Table 3 ) (see Table, Online Resource 2, which describes the agestandardized prevalence of the individual components of the metabolic syndrome and overweight and obesity by area, altitude, region, and socioeconomic quintiles and by gender).

\section{Overweight and MetS by altitude}

Population that lived 0-500 MASL, had the highest prevalence of MetS $(p<0.001)$, hypertension $(p<0.001)$ and hyperglycemia $(p<0.001)$ of all altitude regions (Tables 2 and 3), whereas those living 501-1500 MASL had the highest prevalence of low HDL $(p<0.001)$ and the lowest prevalence of hypertension, especially in women (see Table, Online Resource 2, which describes the age-standardized prevalence of the individual components of the metabolic syndrome and overweight and obesity by area, altitude, region, and socioeconomic quintiles and by gender). The population living 501-1500 MASL had a significant higher prevalence of two metabolic abnormalities, while the population living 0-500 MASL had significant higher prevalence of four abnormalities both in men and women (Table 4).

\section{Overweight and MetS by region}

In line with the results for the low altitude, a higher prevalence, both in men and women, of MetS, hypertension, and hyperglycemia were found in the coast and in the Galapagos regions, as compared to the other regions (Tables 2 and $3)$. Also, prevalence of overweight or obesity was higher in the Galapagos region (74.8\%) than in the other regions (61.5-62.8\%) (Fig. 3, Table 3) (see Table, Online Resource 2 , which describes the age-standardized prevalence of the individual components of the metabolic syndrome and overweight and obesity by area, altitude, region, and socioeconomic quintiles and by gender). The coast and the Galapagos also had the highest prevalence of four and five cumulative abnormalities (Table 4). The lowest prevalence of MetS and that of most of the individual components of the MetS were observed in for the population living in the Amazon (26.6\% for MetS) (Tables 2, 3 and 4). In contrast, the Amazon region had the highest prevalence of low HDL (66.6\%) of all regions, mainly among women living in the Amazon (75.7\%). Due to the unexpected high prevalence of low HDL-cholesterol, a correlation between cholesterol and HDL levels was performed in the amazon population. There was a positive correlation between total cholesterol and HDL-cholesterol only in women (Fig. 3).

\section{Overweight and MetS by economic status}

The lowest quintile (Q1) of economic status had the lowest prevalence of overall MetS (Table 2), and of overweight or obesity and each of the individual MetS components 
Table 3 Crude and age-standardized prevalence of the individual components of the metabolic syndrome and overweight and obesity

Individual components of the metabolic syndrome

\begin{tabular}{|c|c|c|c|c|c|c|}
\hline & Abdominal obesity & Hypertriglyceridemia & Low HDL cholesterol & High blood pressure & Hyperglycemia & $\mathrm{BMI}>25 \mathrm{~kg} / \mathrm{m}^{2}$ \\
\hline Crude & $69.2(67.5-70.8)$ & $34.3(33.1-35.5)$ & $59.8(58.4-61.3)$ & $22.8(21.8-23.8)$ & $18.9(18.0-19.9)$ & $66.5(64.9-68.1)$ \\
\hline \multicolumn{7}{|l|}{ Gender } \\
\hline Men & $46.6(44.4-48.9)$ & $39.5(37.5-41.5)^{\mathrm{I}}$ & $45.9(43.7-48.1)$ & $27.1(25.4-28.8)^{\mathbb{I}}$ & $16.4(15.0-17.7)$ & $57.4(54.9-59.8)$ \\
\hline Women & $74.0(71.9-76.0)^{\beta}$ & $26.2(24.9-27.4)$ & $67.9(65.9-69.9)^{\beta}$ & $14.6(13.6-15.6)$ & $15.2(14.2-16.1)$ & $64.6(62.6-66.5)^{\beta}$ \\
\hline \multicolumn{7}{|l|}{ Area } \\
\hline Urban & $66.0(64.0-68.0)^{\mathrm{I}}$ & $33.0(31.6-34.4)^{\mathrm{I}}$ & $60.7(58.9-62.6)$ & $20.5(19.3-21.6)^{\text {I }}$ & $17.2(16.2-18.2)^{\mathrm{I}}$ & $65.0(63.0-66.9)^{\text {II }}$ \\
\hline Rural & $60.2(57.8-62.7)$ & $27.1(25.4-28.7)$ & $58.1(55.7-60.5)$ & $16.9(15.6-18.3)$ & $13.0(11.8-14.2)$ & $56.6(54.2-59.0)$ \\
\hline \multicolumn{7}{|l|}{ Altitude } \\
\hline $0-500$ & $65.6(63.2-68.0)$ & $30.6(29.0-32.2)$ & $60.2(57.9-62.5)$ & $21.2(19.8-22.6)^{\ddagger}$ & $20.4(19.0-21.7)^{\ddagger}$ & $63.3(60.9-65.6)$ \\
\hline $501-1500$ & $64.0(60.4-67.7)$ & $29.6(27.1-32.1)$ & $65.4(61.7-69.1)^{! !}$ & $11.3(9.8-12.9)$ & $11.0(9.5-12.5)$ & $62.6(59.0-66.2)$ \\
\hline$>1500$ & $63.2(60.8-65.7)$ & $31.6(29.9-33.3)$ & $58.5(56.2-60.8)$ & $17.7(16.4-19.0)^{\alpha}$ & $10.6(9.7-11.6)$ & $61.9(59.5-64.3)$ \\
\hline \multicolumn{7}{|l|}{ Subregion } \\
\hline Highland & $63.8(61.5-66.0)$ & $31.9(30.4-33.5)$ & $58.8(56.6-60.9)$ & $17.7(16.5-18.8)^{+}$ & $11.3(10.3-12.2)$ & $62.2(60.0-64.4)$ \\
\hline Coast & $65.2(62.2-68.1)$ & $30.6(28.6-32.6)$ & $58.3(55.5-61.0)$ & $23.3(21.5-25.0)^{*}$ & $23.1(21.4-24.8)^{*}$ & $62.8(60.0-65.7)$ \\
\hline Amazon & $62.9(59.5-66.3)$ & $28.7(26.4-31.0)$ & $66.6(63.1-70.1)^{\pi}$ & $10.9(9.5-12.3)$ & $9.1(7.8-10.4)$ & $61.5(58.2-64.9)$ \\
\hline Galapagos & $76.4(66.9-85.9)^{*}$ & $29.8(23.9-35.8)$ & $65.2(56.4-74.0)$ & $22.4(17.2-27.5)^{+}$ & $30.8(24.7-36.8)^{*}$ & $74.8(65.4-84.3) *$ \\
\hline \multicolumn{7}{|c|}{ Economic status quintile } \\
\hline Q1 & $55.6(52.5-58.6)$ & $23.9(21.8-25.9)$ & $55.9(52.8-59.0)$ & $16.2(14.5-17.8)$ & $13.1(11.6-14.6)$ & $53.3(50.2-56.3)$ \\
\hline Q2 & $65.7(62.4-69.0)^{\ddagger}$ & $29.5(27.3-31.7)^{\ddagger}$ & $61.1(57.9-64.3)$ & $17.5(15.8-19.2)$ & $14.3(12.7-15.8)$ & $62.8(59.5-66.0)^{\ddagger}$ \\
\hline Q3 & $66.5(63.0-70.0)^{\ddagger}$ & $33.0(30.5-35.5)^{\ddagger}$ & $63.3(59.9-66.7)^{\ddagger}$ & $18.7(16.9-20.6)$ & $15.7(14.0-17.4)$ & $64.1(60.7-67.5)^{\ddagger}$ \\
\hline Q4 & $68.5(64.8-72.1)^{\ddagger}$ & $35.1(32.5-37.8)^{\ddagger}$ & $62.7(59.1-66.2)^{\ddagger}$ & $19.5(17.5-21.4)$ & $16.9(15.1-18.7)^{\ddagger}$ & $68.4(64.7-72.0)^{\ddagger}$ \\
\hline Q5 & $67.1(63.2-70.9)^{\ddagger}$ & $34.1(31.3-36.8)^{\ddagger}$ & $59.6(56.0-63.2)$ & $18.8(16.7-20.8)$ & $14.5(12.7-16.3)$ & $66.4(62.6-70.2)^{\frac{1}{4}}$ \\
\hline
\end{tabular}

Results are age-standardized rate $(95 \% \mathrm{CI})$. Significant differences $(p$ value $<0.05)$ compared to men ${ }^{\beta}$, women ${ }^{\mathbb{I}}$, rural ${ }^{\mathbb{I}}$, 501-1500 and $>1500^{\ddagger},>1500^{! !}, 501-1500^{\alpha}$, Amazon $^{+}$, Highland and Amazon*, Highland and Coast ${ }^{\pi}$, and to Q1 ${ }^{\ddagger}$

(Table 3). As presented in Table 2 and Fig. 4, there is a gradient of MetS by economic status, where Q4 showed the highest prevalence. When comparing SES and MetS stratified by gender, we see that among men, Q1 showed the lowest prevalence but differences between the other quintiles (Q2-Q5) were generally small. In women, MetS showed a lower prevalence in Q1 but also in quintile Q5, compared to the other quintiles (Fig. 4 and Table, Online Resource 2 , which describes the age-standardized prevalence of the individual components of the metabolic syndrome and overweight and obesity by area, altitude, region, and socioeconomic quintiles and by gender).

\section{The dangerous triads}

The dangerous triads were more prevalent in men (10.5 vs 5.6), urban population (5.8 vs 2.9), and at low altitude (5.9 vs 2.2 and 3.2), whereas the lowest prevalence was in the amazon region (1.8 vs 3.4 Highlands, 6.8 Coast, and 7.1 Galapagos) and in the lower socioeconomic quintile Q1 (4.6 vs $8.2 \mathrm{Q} 4$, or $8.1 \mathrm{Q} 5$ ) (see Table, Online Resource 3, which shows the crude and age-standardized prevalence of the dangerous triads).

\section{Discussion}

We showed that MetS is present overall in more than $30 \%$ of the adult population of Ecuador between 18 and 59 years old, and that around $85 \%$ of the population has at least one metabolic abnormality defined as either altered glucose metabolism, dyslipidemia, high blood pressure, or abdominal obesity. The prevalence of overweight, obesity, and MetS triple with age, where the prevalence from 18 to 29 is around $16 \%$ and increases to approximately $50 \%$ at the age group 50-59. Abdominal obesity and low HDL-cholesterol are the most common metabolic abnormalities in Ecuador, with approximately $65 \%$ and $60 \%$, respectively. Besides highlighting the difficult public health problem that the overweight and MetS represent in Ecuador, in this study, we address in this study significant differences between populations that should be taken into consideration to establish population-based strategies to combat this serious health problem with strong economic implications.

The high prevalence of overweight and obesity in the general Ecuadorian adult population is particularly important in the Galapagos and the Coast regions. These regions also had around twice the prevalence of the dangerous triads. This 
Table 4 Crude and age-standardized prevalence of one or more components of the metabolic syndrome

Accumulative risk factors of the metabolic syndrome

\begin{tabular}{|c|c|c|c|c|c|c|}
\hline & 0 & 1 & 2 & 3 & 4 & 5 \\
\hline Crude & $13.2(12.6-13.9)$ & $22.3(21.5-23.2)$ & $28.6(27.5-29.6)$ & $21.1(20.2-22.0)$ & $11.7(10.9-12.4)$ & $3.1(2.7-3.5)$ \\
\hline \multicolumn{7}{|l|}{ Gender } \\
\hline Men & $25.2(23.6-26.8)^{\mathbb{I}}$ & $22.8(21.3-24.3)$ & $19.9(18.5-21.4)$ & $18.2(16.8-19.6)$ & $11.2(10.1-12.3)^{\mathbb{I}}$ & $2.7(2.1-3.2)$ \\
\hline Women & $10.2(9.4-11.0)$ & $25.5(24.2-26.7)$ & $33.6(32.2-35.0)^{\pi}$ & $20.0(18.9-21.0)$ & $8.6(7.9-9.3)$ & $2.2(1.8-2.6)$ \\
\hline \multicolumn{7}{|c|}{ Area and altitude } \\
\hline Urban & $14.7(13.8-15.6)$ & $23.1(21.9-24.3)$ & $28.5(27.3-29.8)$ & $20.3(19.2-21.3)^{\mathbb{I}}$ & $10.5(9.7-11.3)^{\mathbb{I}}$ & $2.9(2.4-3.3)^{\mathbb{I I}}$ \\
\hline Rural & $17.8(16.4-19.1)^{\beta}$ & $26.7(25.1-28.4)^{\beta}$ & $28.5(26.8-30.2)$ & $17.8(16.5-19.1)$ & $7.7(6.8-8.6)$ & $1.5(1.1-1.8)$ \\
\hline \multicolumn{7}{|l|}{ Altitude } \\
\hline $0-500$ & $14.5(13.4-15.7)$ & $23.5(22.0-24.9)$ & $27.9(26.3-29.5)$ & $20.3(19.0-21.6)$ & $11.1(10.1-12.0)^{\ddagger}$ & $2.7(2.2-3.2)^{\alpha}$ \\
\hline $501-1500$ & $16.2(14.3-18.0)$ & $23.6(21.3-25.8)$ & $32.9(30.2-35.5)^{! !}$ & $18.8(16.8-20.8)$ & $7.1(5.9-8.3)$ & $1.4(0.9-2.0)$ \\
\hline$>1500$ & $16.8(15.5-18.1)$ & $25.8(24.3-27.4)$ & $27.9(26.3-29.5)$ & $19.8(18.4-21.1)$ & $7.9(7.1-8.8)$ & $1.8(1.4-2.2)$ \\
\hline \multicolumn{7}{|l|}{ Subregion } \\
\hline Highland & $16.8(15.7-18.0)^{\delta}$ & $25.1(23.7-26.5)^{\delta}$ & $28.2(26.7-29.7)$ & $19.7(18.4-20.9)$ & $8.4(7.6-9.2)$ & $1.9(1.5-2.3)$ \\
\hline Coast & $14.4(13.0-15.7)$ & $23.6(21.9-25.4)$ & $27.1(25.2-28.9)$ & $20.3(18.6-21.9)$ & $11.6(10.3-12.8)^{\Delta}$ & $3.1(2.5-3.8)^{\Delta}$ \\
\hline Amazon & $15.9(14.2-17.5)$ & $25.1(23.0-27.3)^{\delta}$ & $32.4(30.0-34.8)^{ \pm}$ & $19.2(17.4-21.1)$ & $6.3(5.2-7.4)$ & $1.1(0.6-1.5)$ \\
\hline Galapagos & $10.9(7.3-14.5)$ & $17.7(13.1-22.3)$ & $29.5(23.6-35.4)$ & $22.7(17.5-27.9)$ & $16.5(12.0-20.9)^{\Delta}$ & $2.8(1.0-4.6)$ \\
\hline \multicolumn{7}{|c|}{ Economic status } \\
\hline Q1 & $19.7(17.9-21.6)^{*}$ & $28.3(26.1-30.5)^{\phi}$ & $28.3(26.1-30.5)$ & $16.1(14.4-17.7)$ & $6.3(5.2-7.3)$ & $1.3(0.8-1.7)$ \\
\hline Q2 & $15.2(13.6-16.8)$ & $24.6(22.6-26.7)$ & $29.8(27.6-32.1)$ & $19.5(17.7-21.3)$ & $9.1(7.9-10.4)^{\ddagger}$ & $1.8(1.2-2.3)$ \\
\hline Q3 & $14.3(12.6-15.9)$ & $22.6(20.6-24.7)$ & $28.8(26.5-31.1)$ & $22.3(20.3-24.3)^{\ddagger}$ & $9.9(8.6-11.3)^{\ddagger}$ & $2.1(1.4-2.7)$ \\
\hline Q4 & $14.2(12.5-15.8)$ & $22.1(20.0-24.2)$ & $27.8(25.4-30.1)$ & $22.0(19.9-24.1)^{\ddagger}$ & $10.6(9.2-12.1)^{\ddagger}$ & $3.3(2.5-4.1)^{\mathrm{K}}$ \\
\hline Q5 & $14.8(13.0-16.6)$ & $23.8(21.5-26.1)$ & $29.0(26.5-31.6)$ & $19.8(17.8-21.9)^{\ddagger}$ & $10.1(8.6-11.5)^{\ddagger}$ & $2.5(1.8-3.2)^{\ddagger}$ \\
\hline
\end{tabular}

Results are age-standardized rate $(95 \% \mathrm{CI})$. Significant differences $(p$ value $<0.05)$ compared to women ${ }^{\mathbb{I}}, \operatorname{men}^{\pi}$, urban ${ }^{\beta}$, rural $^{\mathbb{I}}, 501-1500$ and $>1500^{\ddagger}, 0-500$ and $>1500^{! !}, 501-1500^{\alpha}$, Galapagos ${ }^{\delta}$, Highland and Coast ${ }^{ \pm}$, Highland and Amazon ${ }^{\Delta}, \mathrm{Q}^{-}-\mathrm{Q} 5^{*}, \mathrm{Q}^{2}$ and Q4 ${ }^{\phi}, \mathrm{Q} 1^{\ddagger}$ and to Q1 and $\mathrm{Q}^{\mathrm{K}}$

Fig. 3 Correlation of total cholesterol and HDL. a In men, Spearman's correlation coefficient $0.04, p 0.24$, and $\mathbf{b}$ in women, Spearman's correlation coefficient $0.26, p<0.001$

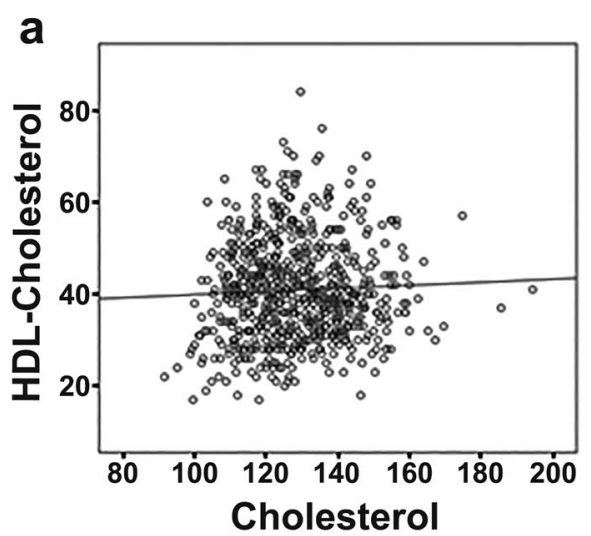

finding in coastal areas is puzzling, since the diet is rich in sea food [20], which is considered to be a beneficial factor preventing the MetS [21]. Apparently other lifestyle factors (e.g., a high consumption of excess sugar and processed foods, a high intake of carbs and salt, and a sedentary and urbanized lifestyle in coastal cities) overrule the beneficial diet rich in sea food. Consequently, the coast and Galápagos regions have the highest risk of morbidity and mortality



of the Ecuadorian population [6]. Preventive efforts should be mainly focused on reducing the blood pressure, highly prevalent in these regions, which is a key risk factor for a CVD event.

The population living in the Amazon region had the lowest prevalence of the individual metabolic syndrome MetS components, except for low HDL-cholesterol for which this region had the highest prevalence among all the altitudes. 


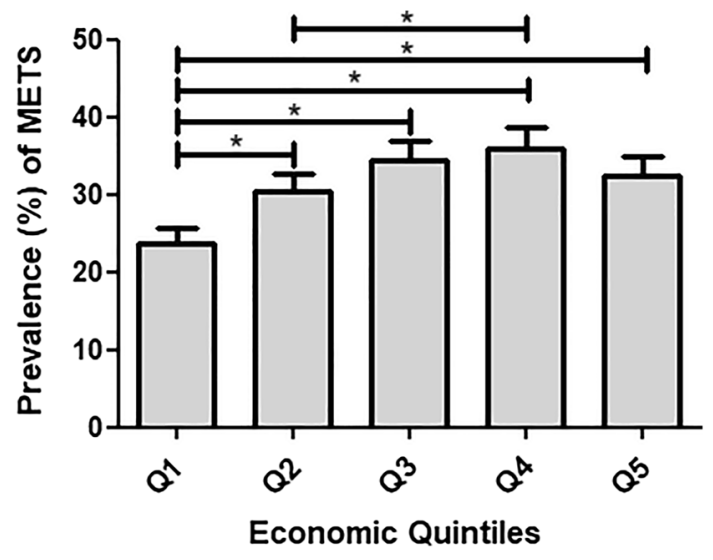

Fig. 4 Mets by the socioeconomic status. *Significant differences between groups $(p<0.05)$

Since the Amazon region is less urbanized, we may speculate that a more rural lifestyle may have a beneficial effect to prevent the development of the MetS. Consequently, a more active lifestyle using a diet low in cholesterol and based on natural ingredients without usage of excess sugar and processed foods plays a role in MetS low prevalence in the Amazon area. The correlation of low total cholesterol with low HDL-cholesterol levels found in the Amazon population (be it only in women) could then also explain the high prevalence of low HDL-cholesterol, since cholesterol is necessary in the synthesis of HDL [22]. Another possible mechanism of this special lipidemic profile of the Amazon indigenous population could be a genetic variation causing lower HDL-cholesterol levels, as has been described previously in the literature [23].

Besides the differences in regions, this study showed a higher prevalence of MetS and overweight in urban compared to rural areas. This is in agreement with evidence from the other studies on a higher prevalence in urban areas, in both developed and developing countries [13, 24]. However, a recent publication on Iranian population described an increased prevalence of MetS and its components in rural compared to urban areas [25]. Inadequate physical activity, higher intake of sugar-enriched beverages and fast food, and low intake of fruit and vegetables are some factors that take part in urbanization lifestyle that account for the high prevalence of MetS and its components found in the urban population.

With respect to socioeconomic status, the population with the lowest socioeconomic status had the lowest prevalence of MetS and almost all the individual components, while the high-income population had the worst metabolic profile. A similar SES pattern was found in a nation-wide study performed in Mexico [26]. In our study, however, women in the highest and lowest socioeconomic quintiles both had similar low metabolic risks, whereas for men, only the lowest socioeconomic status was associated with better metabolic health (Fig. 5). This crucial difference in SES between women and men was not reported in the Mexican population [26]. In this study, only men showed the characteristic pattern of undeveloped countries where belonging to a high-income class is correlated to the development of MetS [27, 28], while women agreed with a protective effect of high social class to MetS described elsewhere [29-32]. A difference between men and women in this respect has been reported previously $[33,34]$. It is important to highlight that in developed countries, there is a transition where the higher socioeconomic class is reducing their metabolic risk, while it is increasing in lower social classes [32, 35], likely illustrating the adoption of a healthier lifestyle in the more effluent classes. We hypothesize that this change is already happening in Ecuador, since the women in the highest socioeconomic class showed a lower prevalence of MetS compared to the high-middle class which showed the highest prevalence. Unequal health access and social benefits will hamper the possible positive effects of preventive government measures to the population with the low income and middle income, resulting in a shift of better health in higher rather than lower socioeconomic groups.

In Latin America, there are a few nationally representative surveys addressing cardiometabolic risk factors [7, 8]. Obesity, high blood pressure, dyslipidemia, and diabetes are major public health problems globally. Despite this, there is still not enough information on the variation of the prevalence between and within countries and on the changes of these risk factors in time. To better understand this global pandemic, it will be advisable to know the differences between populations that will result in more focused research and directed policies to reduce the enormous problem that these non-communicable diseases represent. Additionally, the prevalence of risk factors is increasing in low- and middle-income countries, while in high-income countries, they have been suggested to have reached a plateau [36]. Consequently, as overweight and MetS increases, the risk of diabetes and cardiovascular disease morbidity and mortality will increase in parallel in these low- and middleincome countries [37-41]. Although, the lifestyle differences described above can explained partially the results, which is not clear how much these differences account for the demographic variations in the prevalence of the MetS, and overweight and obesity, and more importantly how they can be modified.

\section{Strengths and limitations}

Strengths of our study include that the ENSANUT-ECU study was performed in a very large-scale nation-wide 
a

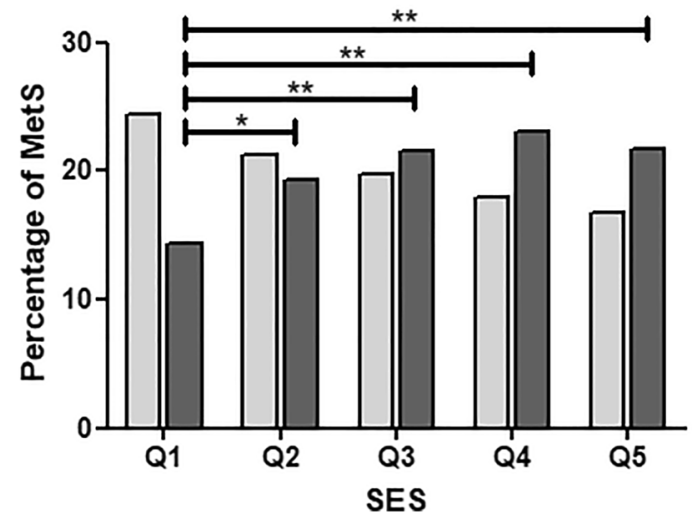

b

Women without Mets

Women with Mets



Fig. 5 Mets in women and men by the socioeconomic status. a In men and $\mathbf{b}$ in women. ${ }^{*} p<0.05, * * p<0.001$

sample across the entire Ecuadorian country, using standardized protocols, instruments, and biomarkers, which enables the exploration of the heterogeneity across age, gender, and geographic and socioeconomic groups. Strict training and supervision were performed to ensure adequate data collection. The results thus offer exceptionally informative evidence on the prevalence of MetS and the sociodemographic determinants of the Ecuadorian society. An important limitation regarding the prevalence of metabolic syndrome is that the study did not include the population older than 59 years. This means that the found MetS prevalence is probably relatively low, since prevalence increases with aging. Another limitation is that we only measured all participants at one point in time and we cannot, therefore, provide evidence for changes in time within persons or generations.

\section{Conclusions}

In conclusion, our results showed a high prevalence of overweight, obesity, and the MetS in Ecuador, and that there are crucial differences between region, area, socioeconomic status, and importantly by gender within the Ecuadorian population. Particularly, urban-dwelling men in the coastal regions of high socioeconomic state are at high risk to develop the MetS, while indigenous individuals living in the Amazon region are at the lowest risk. How this will impact further development of CVD in these separate populations need to be studied. Also, further studies evaluating the impact of diet, physical activity, socioeconomic status, and education could help to identify the factors responsible for the differences between gender, areas, and regions. Furthermore, the described prevalence of different metabolic risk factors for each region will allow to develop more targeted prevention strategies; for example, a diet strategy in
Ecuador will be totally different between the Amazon region where it might be necessary to increase the HDL levels than for the coastal region where focus would be on reducing, in particular, the blood pressure.

Author contributions All authors critically reviewed the manuscript and read and approved the manuscript; WF provided the database of the ENSANUT-ECU study; JPG performed the statistical analysis; JPG and TV wrote the manuscript; TV, LBR, TM, HD, WF, and OHF provided input regarding the interpretation of the analyses; JPG, TV, and OHF had primary responsibility for the final content of the manuscript.

Funding This publication was supported by the Institutional Cooperation between the higher education institutions of the Wallonia-Brussels Federation (Belgium) and the Universidad Central del Ecuador funded through the Academie de Recherche et d'Enseignement Superieur (ARES).

Data availability The data are available online at the web page of the Ecuadorian Health Ministry.

\section{Compliance with ethical standards}

Conflict of interest The authors declare no conflict of interest.

Ethical approval Not applicable.

Informed consent Not applicable.

Open Access This article is licensed under a Creative Commons Attribution 4.0 International License, which permits use, sharing, adaptation, distribution and reproduction in any medium or format, as long as you give appropriate credit to the original author(s) and the source, provide a link to the Creative Commons licence, and indicate if changes were made. The images or other third party material in this article are included in the article's Creative Commons licence, unless indicated otherwise in a credit line to the material. If material is not included in the article's Creative Commons licence and your intended use is not permitted by statutory regulation or exceeds the permitted use, you will 
need to obtain permission directly from the copyright holder. To view a copy of this licence, visit http://creativecommons.org/licenses/by/4.0/.

\section{References}

1. Popkin B, Adair L, Ng S (2012) NOW AND THEN: the global nutrition transition: the pandemic of obesity in developing countries. nutr rev 70(1):3-21

2. Popkin BM, Adair LS, Ng SW (2012) Global nutrition transition and the pandemic of obesity in developing countries. Nutr Rev 70(1):3-21. https://doi.org/10.1111/j.1753-4887.2011.00456.x

3. Ng M, Fleming T, Robinson M, Thomson B, Graetz N, Margono $C$ et al (2014) Global, regional, and national prevalence of overweight and obesity in children and adults during 1980-2013: a systematic analysis for the Global Burden of Disease Study 2013. Lancet 384(9945):766-781

4. Farag YMK, Gaballa MR (2011) Diabesity: an overview of a rising epidemic. Nephrol Dial Transplant 26(1):28-35

5. Jaacks LM, Siegel KR, Gujral UP, Narayan KMV (2016) Type 2 diabetes: a 21st century epidemic. Best Pract Res Clin Endocrinol Metab 30(3):331-343. https://doi.org/10.1016/j. beem.2016.05.003

6. Franco OH, Massaro JM, Civil J, Cobain MR, O’Malley B, D'Agostino RB (2009) Trajectories of entering the metabolic syndrome: the framingham heart study. Circulation 120(20):1943-1950

7. Márquez-Sandoval F, Macedo-Ojeda G, Viramontes-Hörner D, Fernández Ballart J, Salas Salvadó J, Vizmanos B (2011) The prevalence of metabolic syndrome in Latin America: a systematic review. Public Health Nutr 14(10):1702-1713. https://www. journals.cambridge.org/abstract_S1368980010003320

8. Cuevas A, Alvarez V, Carrasco F (2011) Epidemic of metabolic syndrome in Latin America. Curr Opin Endocrinol Diabetes Obes 18(2):134-138. https://content.wkhealth.com/linkback/ openurl?sid=WKPTLP:landingpage $\&$ an $=01266029-20110$ 4000-00007

9. Food and Agriculture Organization of the United Nations (2006) The double burden of malnutrition, vol. 20, World Health Organization. https://books.google.com/books? $\mathrm{id}=\mathrm{mamt} 4$ lfXRuwC\&pg=PA187\&dq=dietary+oil+intake+socioecono $\operatorname{mic} \& \mathrm{hl}=\& \mathrm{~cd}=6 \&$ source $=$ gbs $\_$api

10. Boissonnet C, Schargrodsky H, Pellegrini F, Macchia A, Marcet Champagne B, Wilson E et al (2011) Educational inequalities in obesity, abdominal obesity, and metabolic syndrome in seven Latin American cities: the CARMELA Study. Eur J Cardiovasc Prev Rehabil 18(4):550-556. https://doi.org/10.1177/1741826710 389418

11. Sempértegui F, Estrella B, Tucker KL, Hamer DH, Narvaez X, Sempértegui M et al (2011) Metabolic syndrome in the elderly living in marginal peri-urban communities in Quito, Ecuador. Public Health Nutr 14(5):758-756 (Elderly; metabolic syndrome; Ecuador; micronutrient deficiency; C-reactive protein)

12. Paz-y-Miño C, Guillén MJ, Leone PE (2014) Genetics and genomic medicine in Ecuador. Mol Genet Genomic Med 2(2):8594. https://doi.org/10.1002/mgg3.73

13. Gu D, Reynolds K, Wu X, Chen J, Duan X, Reynolds RF, Paul K, Whelton JH (2005) Prevalence of the metabolic syndrome and overweight among adults in China. Lancet 365:8

14. Freire W, Ramirez-Luzuriaga M, Belmont P, Mendieta M, SilvaJaramillo M, Romero N et al (2014) Tomo I: Encuesta Nacional de Salud y Nutrición de la población ecuatoriana de cero a 59 años. ENSANUT-ECU 2012, First. Quito, p 722
15. Freire WB, Belmont P, Lepez-Cevallos DF, Waters WF (2015) Ecuador's national health and nutrition survey: objectives, design, and methods. Ann Epidemiol. 25(11):877-878. https:// doi.org/10.1016/j.annepidem.2015.08.009

16. De Onis M, Habicht JP (1996) Anthropometric reference data for international use: recommendations from a World Health Organization Expert Committee. Am J Clin Nutr 64(4):650-658

17. The Obesity Society (1998) Guidelines for management of the obese and overweight. Obes Res 6:51S-179S

18. Alberti KGMM, Eckel RH, Grundy SM, Zimmet PZ, Cleeman JI, Donato KA et al (2009) Harmonizing the metabolic syndrome: a joint interim statement of the international diabetes federation task force on epidemiology and prevention; National heart, lung, and blood institute; American heart association; World heart federation. Int Circ 120(16):1640-1645

19. Instituto Nacional de Estadística y Censos (INEC) (2017) ResultadosIInstituto Nacional de Estadística y Censos. https:// www.ecuadorencifras.gob.ec/resultados/. Accessed 28 Jun 2017

20. Del Brutto OH, Mera RM, Ha J, Gillman J, Zambrano M, Castillo PR (2016) Dietary fish intake and sleep quality: a populationbased study. Sleep Med 17:126-128. https://linkinghub.elsevier. com/retrieve/pii/S1389945715020225

21. Tørris C, Molin M, Smastuen MC (2014) Fish consumption and its possible preventive role on the development and prevalence of metabolic syndrome-a systematic review. Diabetol Metab Syndr 6:1

22. Ve W, Lichtenstein AH, Welty FK, Li Z, Lamon-fava S, Dolnikowski GG et al (1999) Decreases HDL ApoA-I secretion. Arterioscl Thromb Vasc Biol 1999:918-925

23. Frikke-Schmidt R, Nordestgaard BG, Jensen GB, TybjaergHansen A (2004) Genetic variation in ABC transporter A1 contributes to HDL cholesterol in the general population. J Clin Investig 114(9):1343-1353. https://www.jci.org/articles/view/20361

24. de Carvalho-Vidigal F, Bressan J, Babio N, Salas-Salvadó J (2013) Prevalence of metabolic syndrome in Brazilian adults: a systematic review. BMC Public Health 13:1198

25. Khosravi-Boroujeni H, Sarrafzadegan N, Sadeghi M, Roohafza H, Talaei M, Ng S-K et al (2017) Secular trend of metabolic syndrome and its components in a cohort of Iranian adults from 2001 to 2013. Metab Syndr Relat Disord 15(3):137-144. https://doi. org/10.1089/met.2016.0073

26. Ponce X, Rodríguez-Ramírez S, Mundo-Rosas V, Shamah T, Barquera S, De Cossio TG (2014) Dietary quality indices vary with sociodemographic variables and anthropometric status among mexican adults: a cross-sectional study. Results from the 2006 national health and nutrition survey. Public Health Nutr 17(8):1717-1728

27. Chakraborty S, Roy S, Rahaman M (2015) Epidemiological predictors of metabolic syndrome in urban West Bengal, India. J Fam Med Prim Care 4(4):535. https://www.jfmpc.com/text. asp?2015/4/4/535/174279

28. Adedoyin RA, Afolabi A, Adegoke OO, Akintomide AO, Awotidebe TO (2013) Relationship between socioeconomic status and metabolic syndrome among Nigerian adults. Diabetes Metab Syndr Clin Res Rev 7(2):91-94. https://doi.org/10.1016/j. dsx.2013.02.014

29. Gannar F, Cabrera de León A, Brito Díaz B, Del Cristo Rodríguez Pérez M, Marcelino Rodríguez I, Ben Dahmen F et al (2015) Social class and metabolic syndrome in populations from Tunisia and Spain. Diabetol Metab Syndr 7(1):88. https://www.dmsjo urnal.com/content/7/1/88

30. Cozier YC, Albert MA, Castro-Webb N, Coogan PF, Ridker P, Kaufman HW et al (2016) Neighborhood socioeconomic status in relation to serum biomarkers in the Black Women's Health Study. J Urban Heal New York Acad Med 93(2):279-291 
31. Zhan Y, Yu J, Chen R, Gao J, Ding R, Fu Y et al (2012) Socioeconomic status and metabolic syndrome in the general population of China: a cross-sectional study. BMC Public Health 12(1):921. https://doi.org/10.1186/1471-2458-12-921

32. Blanquet M, Debost-Legrand A, Gerbaud L, De La Celle C, Brigand A, Mioche L et al (2016) Metabolic syndrome and social deprivation: results of a French observational multicentre survey. Fam Pract 33(1): 17-22

33. Chichlowska KL, Rose KM, Diez-Roux AV, Golden SH, McNeill AM, Heiss G (2009) Life course socioeconomic conditions and metabolic syndrome in adults: the atherosclerosis risk in communities (ARIC) study. Ann Epidemiol 19(12):875-883. https:// doi.org/10.1016/j.annepidem.2009.07.094

34. Wu HF, Tam T, Jin L, Lao XQ, Chung RYN, Su XF et al (2017) Age, gender, and socioeconomic gradients in metabolic syndrome: biomarker evidence from a large sample in Taiwan, 2005-2013. Ann Epidemiol 27(5):315-322.e2. https://doi.org/10.1016/j.annep idem.2017.04.003

35. Wells JCK, Cole TJ, Bruner D, Treleaven P (2008) Body shape in American and British adults: between-country and inter-ethnic comparisons. Int J Obes 32(1):152-159. https://doi.org/10.1038/ sj.ijo.0803685

36. World Health Organization. Global status report on noncommunicable diseases (2010) World Health, p 176. https://whqlibdoc. who.int/publications/2011/9789240686458_eng.pdf
37. Galassi A, Reynolds K, He J (2006) Metabolic syndrome and risk of cardiovascular disease: a meta-analysis. Am J Med 119(10):812-819

38. Thorn LM, Forsblom C, Waden J, Saraheimo M, Tolonen N, Hietala KU, Groop PH (2009) Metabolic syndrome as a risk factor for cardiovascular disease, mortality, and progression of diabetic nephropathy in type 1 diabetes. Diabetes Care 2009:950-952

39. Marion AW, Baker AJ, Dhawan A, Wild SH, Byrne CD (2004) Fatty liver disease in children. Arch Dis Child. 333:648-652

40. Shin JA, Lee JH, Lim SY, Ha HS, Kwon HS, Park YM et al (2013) Metabolic syndrome as a predictor of type 2 diabetes, and its clinical interpretations and usefulness. J Diabetes Investig 4(4):334-343

41. Neergaard JS, Laursen JM, Hansen HB, Christiansen C, Becknielsen H, Karsdal MA et al (2016) Metabolic syndrome and subsequent risk of type 2 diabetes and cardiovascular disease in elderly women. Med 2016:36

Publisher's Note Springer Nature remains neutral with regard to jurisdictional claims in published maps and institutional affiliations. 